\title{
Sarcoidosis: social predictors of severity at presentation
}

\author{
D.L. Rabin, B. Thompson, K.M. Brown, M.A. Judson, X. Huang, D.T. Lackland, G.L. Knatterud, \\ H. Yeager Jr, C. Rose, J. Steimel on behalf of the ACCESS Research Group.
}

The ACCESS principal investigators and co-principal investigators: R.P. Baughman, E.A. Bresnitz, R. Cherniak, L. DePalo, G. Hunninghake, M.C. Iannuzzi, C.J. Johnst', G. McLennan, D.R. Moller, R. Musson, L.S. Newman, M.D. Rossman, B.A. Rybicki, A.S. Teirstein, M.L. Terrin, S.E. Weinberger.

Sarcoidosis: social predictors of severity at presentation. D. L. Rabin, B. Thompson, K. M. Brown, M.A. Judson, X. Huang, D.T. Lackland, G.L. Knatterud, H. Yeager Jr, C. Rose, J. Steimel on behalf of the ACCESS Research Group. (C) ERS Journals Ltd 2004.

ABSTRACT: To determine relationships among social predictors and sarcoidosis severity at presentation, demographic characteristics, socioeconomic status, and barriers to care, A Case-Control Etiologic Study of Sarcoidosis (ACCESS) was set up.

Patients self-reported themselves to be Black or White and were tissue-confirmed incident cases aged $\geqslant 18$-yrs-old $(n=696)$ who had received uniform assessment procedures within one of $\mathbf{1 0}$ medical centres and were studied using standardised questionnaires and physical, radiographical, and pulmonary function tests. Severity was measured by objective disease indicators, subjective measures of dyspnoea and short form-36 subindices.

The results of the study showed that lower income, the absence of private or Medicare health insurance, and other barriers to care were associated with sarcoidosis severity at presentation, as were race, sex, and age. Blacks were more likely to have severe disease by objective measures, while women were more likely than males to report subjective measures of severity. Older individuals were more likely to have severe disease by both measures.

In conclusion, it was found that low income and other financial barriers to care are significantly associated with sarcoidosis severity at presentation even after adjusting for demographic characteristics of race, sex, and age.

Eur Respir J 2004; 24: 601-608.
Correspondence: D.L. Rabin

Division of Community Health Care Studies, Georgetown University School of Medicine 3800 Reservoir Road, N.W

Kober-Cogan 418

Washington D.C.20007

Fax: 12026877230

E-mail: rabind@georgetown.edu

Keywords: Barriers to care

income

insurance

sarcoidosis

severity

socioeconomic status

Received: June 202003

Accepted after revision: June 302004

Supported by contracts (NO1-HR-56065, $56067,56069,56070,56071,56072,56073$, $56074,56075)$ from the National Heart, Lung, and Blood Institute, USA.
Social predictors including demographic characteristics, socioeconomic status (SES), and barriers to care affect health status $[1,2]$. SES is used to classify people by health status, but SES-related health status may result from social opportunity and health behaviour. Both may be affected by barriers to healthcare, particularly financial limitations on access to medical services. Low SES and barriers to healthcare are associated with a worse disease course and outcomes for some degenerative, pulmonary, infectious, and malignant diseases. Sarcoidosis occurs more frequently and has a more severe disease course among Blacks than Whites [3]. Blacks are more likely to be of low SES and to be insured less well. Cross-sectional studies of ambulatory sarcoidosis patients showed education, income and/or public health insurance to be related to disease severity [4]. Among Black patients, municipal hospital ambulatory sarcoidosis patients had more severe illness than university hospital sarcoidosis patients [5]. By contrast, a study of hospitalised sarcoidosis patients in South Carolina showed no associations of disease severity with measures of income and education [6].

Nothing is known about the associations among severity of sarcoidosis at presentation (time of diagnosis), SES and barriers to care. A Case-Control Etiologic Study of Sarcoidosis (ACCESS) was a prospective, multicentre, case-control study of sarcoidosis of patients enrolled within 6 months of diagnosis [7], providing an opportunity to test the association of SES and demographic measures and barriers to care with disease severity at presentation.

\section{Methods}

\section{Patient population}

From November 1996 to June 1999, ACCESS enrolled 736 incident cases and 706 random-digit-dialing (RDD) matched controls from 10 participating centres. Cases must have had a tissue-confirmed diagnosis of sarcoidosis within 6 months of their recruitment into the study and did not have exclusion criteria that may have indicated other causes of granulomatous disease (i.e. negative stains for mycobacterial and fungal infection). This analysis was limited to the 696 Black or White sarcoidosis cases for which there were complete data on the variables entered into the logistical regression analyses.

\section{Measures}

Following the provision of informed consent, patients received a thorough history, physical, and laboratory examination. Trained research staff administered a standardised 
questionnaire on: demographic and SES characteristics, medical insurance and other barriers to medical care, quality of life (QoL), general and sarcoidosis-related medical and occupational history, and home, avocational, and vocational exposures.

Sarcoidosis severity variables. The dependent variable objective measures of disease severity for this analysis were: 1) Extent of organ involvement: disease in nonthoracic lymph nodes, kidneys, heart, skin (other than erythema nodosum). Extent of disease was classified as disease in one organ system, two organ systems, or three or more organ systems [8]. 2) Chest radiograph staging; based on radiographs that were read by site radiologists and investigators and classified by site investigators into a modified Scadding scale [9]. 3) Spirometry; pulmonary function spirometry studies met American Thoracic Society standards, with per cent predicted values calculated using reference values specific for Blacks and Whites [10] and per cent predicted forced vital capacity (FVC) and forced expiratory volume in one second (FEV1) measurements which were grouped into four categories of severity which were: $<50,50-69.9,70-79.9$ and $\geqslant 80 \%$. 4) The dependent variable subjective measures were dyspnoea (score of $0-4$ ) for activities causing shortness of breath [11] and the subscales of the short form (SF)-36: physical functioning, physical role limitations, general health, and social functioning [12]. Physical functioning and general health scores were grouped into quartiles, with the highest quartile of scores representing the best functioning.

Social predictor variables. Demographic characteristics and barriers to care (independent variables) included: race ( $1=$ Black, $0=$ White); sex $(1=$ female, $0=$ male); age $(1=\geqslant 40 \mathrm{yrs}$, $0=\leqslant 40$ yrs); yearly family income was coded as two indicator variables $\quad(1=<$ US $\$ 20,000$ and 0 otherwise, and $1=\mathrm{US} \$ 20,000-49,999$ and 0 otherwise); type of health insurance ( $1=$ no insurance, public insurance, or Medicaid; $0=$ private insurance or Medicare); type of doctor (1=no regular doctor, $0=$ general practitioner or specialist); experienced delay in getting medication $(1=y e s, 0=$ no); experienced other barriers to medical care $(1=$ couldn't see a doctor when wanted to and cost of medical care is a worry, $0=$ neither a problem); had a regular place for medical care $(1=$ no regular place or emergency room, $0=$ doctor's office or clinic); and missed more than one medical appointment in the last six months $(1=y e s, 0=$ no).

\section{Statistical analysis}

Means, and SD were used to describe continuous variables by income and type of insurance and t-tests were used to compare variables. Percentages and Chi-squared tests were used to test for income or insurance type differences in categorical measures.

To investigate the effects of SES, demographic, and barriers to care variables (predictor or independent variables) on sarcoidosis severity (dependent variables), each of the nine severity variables (Scadding score, dyspnoea level, number of organs involved, FEV1 \% pred, FVC \% pred, physical functioning score, physical role limitation score, general health quartile, and social functioning quartile) were all tested, separately in the logistical regression model shown in table 1 [13], using SAS PROC LOGISTICS procedures [14].

Ordinal severity variables were coded so that a higher number indicated greater severity. Stepwise, backward model selection procedures were used. Terms for race, sex, and age were forced to remain in the model, but other nonsignificant $(p>0.05)$ variables were dropped. To adjust for possible
Table 1.-Logistical regression model

Specific severity variables

Race

Sex

Age

Education

Income

Type of insurance

Type of doctor

Delay in getting medications

Other barriers to medical care

Regular place for medical care

Missed appointments $>1$

The sum of the above variables were used as the logistic regression model.

comorbidity, concomitant disease/symptoms were investigated and where significant univariately, included in the logistical regression model. Concomitant disease/symptom variables included: chronic bronchitis, allergies, heart disease, high blood pressure, liver disease, arthritis, lupus erythematosis, smoking, height, weight, heart rate, respiratory rate, self-assessment of health status, mood, and social support. Coefficients from the logistical models were used to estimate the relative increase in the odds (OR) for higher values of a predictor associated with the presence of a characteristic. For example, an OR of 1.00 indicated that there is no difference between variables, and one of 2.00 indicated a two-fold difference [13]. A large number of analyses were performed in this study. The primary comparisons between the disease severity dependent variables and the demographic, income, and barriers to care independent variables were tested at the $0.05 \alpha$-level. All other analyses were performed in an attempt to adjust the primary findings and were performed at the 0.05 $\alpha$-level of significance. Interpretations of OR for the adjustment variables should be made with caution due to the possibility that some of the associations may be present by chance due to the large number of tests that were performed

\section{Results}

\section{Descriptive analysis}

The study population had more Whites (53\%), females $(64 \%)$, and people aged $\geqslant 40$ yrs $(54 \%)$ rather than $\leqslant 40$ yrs old $(46 \%)$. Black males and females were more likely to be $<40$ yrs of age; $41 \%$ had more than just high school education, nearly half $(44 \%)$ had annual household incomes of $\geqslant$ US $\$ 50,000$ and $20 \%$ had annual household incomes of $<$ US\$20,000. Among the cases studied, 84\% had private health insurance or Medicare while $9 \%$ had other public insurance/Medicaid or ( $7 \%)$ no insurance.

Income and predictors. Distributions by demographic characteristics, education, barriers to care, and health status (divided into subjective and objective measures) by income are summarised in table 2 . Low-income cases $(<\mathrm{US} \$ 20,000)$ were more likely to be Black, female, have high school education or less, have no or other public insurance, report trouble getting medications, encounter barriers to care and have missed one or more medical appointments in 6 months. Objective severity measures, FEV1 \% pred and FVC \% pred showed that cases with an annual household income $<$ US $\$ 20,000$ were less likely to have normal values than those with higher income $(\mathrm{p}<0.0001$ for FEV1 and $\mathrm{p}=0.0003$ for FVC). Subjective 
Table 2. - Per cent distributions for demographic characteristics, socioeconomic status (SES), barriers to care, and health status by income category

\begin{tabular}{|c|c|c|c|c|c|}
\hline \multirow[t]{2}{*}{ Variable } & \multirow[t]{2}{*}{ Patients $\mathrm{n}$} & \multicolumn{3}{|c|}{ Annual household income US\$ } & \multirow[t]{2}{*}{ p-value } \\
\hline & & $<20,000$ & $20,000-49,999$ & $\geqslant 50,000$ & \\
\hline \multicolumn{6}{|c|}{ Demographical and SES characteristics } \\
\hline \multicolumn{6}{|c|}{ Race } \\
\hline Black & 310 & 34.5 & 42.3 & 23.2 & \multirow[t]{2}{*}{$<0.0001$} \\
\hline White & 386 & 8.3 & 30.3 & 61.4 & \\
\hline \multicolumn{6}{|l|}{ Sex } \\
\hline Female & 447 & 22.6 & 40.0 & 37.4 & \multirow[t]{2}{*}{$<0.0001$} \\
\hline Male & 249 & 15.3 & 27.7 & 57.0 & \\
\hline \multicolumn{6}{|l|}{ Age } \\
\hline$\geqslant 40 \mathrm{yrs}$ & 379 & 16.9 & 35.4 & 47.8 & \multirow[t]{2}{*}{0.05} \\
\hline$<40$ yrs & 317 & 23.7 & 36.0 & 40.4 & \\
\hline \multicolumn{6}{|l|}{ Education } \\
\hline$\leqslant$ High school graduate & 409 & 30.3 & 40.6 & 29.1 & \multirow[t]{3}{*}{$<0.0001$} \\
\hline College graduate & 172 & 7.6 & 32.0 & 60.5 & \\
\hline Post graduate & 115 & 1.7 & 23.5 & 74.8 & \\
\hline Barriers to care & & & & & \\
\hline Insurance status & & & & & \\
\hline None & 49 & 75.5 & 22.4 & 2.0 & $<0.0001$ \\
\hline Other/public & 60 & 68.3 & 33.3 & 8.3 & \\
\hline Private/Medicare & 587 & 10.4 & 38.0 & 51.6 & \\
\hline Trouble getting medication & & & & & \\
\hline Yes & 51 & 47.1 & 33.3 & 19.6 & $<0.0001$ \\
\hline No & 645 & 17.8 & 35.8 & 46.4 & \\
\hline Other barriers & & & & & \\
\hline Yes & 142 & 43.0 & 32.4 & 24.6 & $<0.0001$ \\
\hline No & 554 & 14.1 & 36.5 & 49.5 & \\
\hline Missed $>1$ appointment & & & & & \\
\hline Yes & 74 & 51.3 & 33.8 & 14.9 & $<0.0001$ \\
\hline No & 622 & 16.2 & 35.8 & 47.9 & \\
\hline Health status & & & & & \\
\hline Objective severity & & & & & \\
\hline Number of organ system & & & & & \\
\hline 1 & 349 & 16.6 & 32.4 & 51.0 & 0.006 \\
\hline 2 & 203 & 21.7 & 37.9 & 40.4 & \\
\hline$\geqslant 3$ & 144 & 25.7 & 40.3 & 34.0 & \\
\hline FEV1 \% pred & & & & & \\
\hline$<50$ & 25 & 36.0 & 52.0 & 12.0 & $<0.0001$ \\
\hline $50-69$ & 108 & 29.6 & 29.6 & 40.7 & \\
\hline $70-79$ & 117 & 23.9 & 39.3 & 36.7 & \\
\hline$\geqslant 80$ & 423 & 15.4 & 35.5 & 49.2 & \\
\hline FVC $\%$ pred $^{\top}$ & & & & & \\
\hline$<50$ & 16 & 31.2 & 50.0 & 18.7 & 0.003 \\
\hline $50-69$ & 71 & 36.6 & 36.6 & 26.8 & \\
\hline $70-79$ & 118 & 23.7 & 33.0 & 43.2 & \\
\hline$\geqslant 80$ & 467 & 16.1 & 35.8 & 48.2 & \\
\hline Subjective severity & & & & & \\
\hline Dyspnoea level $^{+}$ & 343 & 10.8 & 34.4 & 54.8 & $<0.0001$ \\
\hline 1 & 233 & 22.7 & 34.8 & 42.5 & \\
\hline 2 & 83 & 34.9 & 44.6 & 20.5 & \\
\hline 3 & 25 & 60.0 & 24.0 & 16.0 & \\
\hline 4 & 11 & 45.4 & 54.5 & 0.0 & \\
\hline Physical function quartil & & & & & \\
\hline 1 & 174 & 39.1 & 39.1 & 21.8 & $<0.0001$ \\
\hline 2 & 165 & 18.8 & 38.2 & 43.0 & \\
\hline 3 & 172 & 15.7 & 24.9 & 49.4 & \\
\hline 4 & 178 & 6.2 & 30.9 & 62.9 & \\
\hline Physical role $\operatorname{limits}^{f}$ & & & & & $<0.0001$ \\
\hline 0 & 214 & 30.8 & 38.8 & 30.4 & \\
\hline 25 & 92 & 20.6 & 39.1 & 40.2 & \\
\hline 50 & 61 & 16.4 & 34.4 & 49.2 & \\
\hline 75 & 70 & 14.3 & 28.6 & 57.1 & \\
\hline 100 & 258 & 13.2 & 34.1 & 52.7 & \\
\hline General health quartile & & & & & \\
\hline 1 & 165 & 29.1 & 41.2 & 29.7 & $<0.0001$ \\
\hline 2 & 165 & 32.1 & 32.7 & 35.1 & \\
\hline
\end{tabular}


Table 2.-(Continued)

\begin{tabular}{|c|c|c|c|c|c|}
\hline \multirow[t]{2}{*}{ Variable } & \multirow[t]{2}{*}{ Patients $n$} & \multicolumn{3}{|c|}{ Annual household income US\$ } & \multirow[t]{2}{*}{ p-value } \\
\hline & & $<20,000$ & $20,000-49,999$ & $\geqslant 50,000$ & \\
\hline 3 & 180 & 11.7 & 38.3 & 50.0 & \\
\hline 4 & 185 & 9.2 & 30.8 & 60.0 & \\
\hline \multicolumn{6}{|c|}{ Social function score ${ }^{++}$} \\
\hline $0-12.5$ & 34 & 38.2 & 55.9 & 5.9 & $<0.0001$ \\
\hline 25 & 41 & 36.6 & 39.0 & 24.4 & \\
\hline 37.5 & 56 & 26.8 & 42.9 & 30.4 & \\
\hline 50 & 90 & 26.7 & 40.0 & 33.3 & \\
\hline 62.5 & 96 & 17.7 & 33.3 & 49.0 & \\
\hline 75 & 98 & 14.3 & 31.6 & 54.1 & \\
\hline 87.5 & 89 & 18.0 & 32.6 & 49.4 & \\
\hline 100 & 191 & 13.1 & 31.9 & 55.0 & \\
\hline
\end{tabular}

Number of patients with data $(\mathrm{n}=696)$ unless otherwise stated. FEV1 \% pred: forced expiratory volume in one second per cent predicted; FVC $\%$ pred: forced vital capacity per cent predicted. ${ }^{\#}: \mathrm{n}=673 ;{ }^{\uparrow}: \mathrm{n}=672 ;{ }^{+}: \mathrm{n}=695 ;{ }^{\S}: \mathrm{n}=689{ }^{f}: \mathrm{n}=695 ;{ }^{\# \#}: \mathrm{n}=695 ;{ }^{++}: \mathrm{n}=695$.

measures of dyspnoea showed only $11 \%$ of lowest income cases reporting level 1 dyspnoea versus $34 \%$ for those of middle and $55 \%$ for those with the highest income $(\mathrm{p}<0.0001)$.

Other subjective measures showed an income effect. Those with $<$ US\$20,000 income were least likely to report normal physical functioning and physical role limits, accounting for only $6 \%$ of those in the highest quartile of physical functioning compared with $63 \%$ in the highest income category. Cases with lowest incomes were least likely to be in the highest quartile of general health (9\%), compared with highest income cases $(60 \%)$. Finally, only $13 \%$ of those with the lowest incomes scored in the highest social functioning category compared with $55 \%$ of those with the highest incomes. All differences were significant $(\mathrm{p}<0.0001)$.

Although not presented here, income was related to the following comorbidities/symptoms: reported liver disease with cases earning <US\$20,000 reporting a greater prevalence of liver disease than cases at the higher income levels (7.9 versus 3.2 versus $2.2 \%$ ), and arthritis with cases reported more frequently in the two lower income groups ( 25 versus 28 versus $18 \%$ ). High blood pressure was also reported more often in the two lowest income groups (29 versus 28 versus $20 \%$ ). All other comorbidities and symptoms were not significantly related to income.

Insurance and predictors. Although not shown, the same variables were tested for health insurance as for income. Comparison of private health insurance/Medicare versus no/ other public insurance showed similar patterns, with p-values $<0.0001$ for most associations except for sex, which was not significantly related to insurance type, and age $<40 \mathrm{yrs}$, which was more strongly associated with no or public insurance $(p<0.001)$. Variables indicating trouble getting medication and barriers to care were significantly associated $(\mathrm{p}<0.0001)$ with no or other public insurance.

By objective severity measures, cases with no or other public insurance had significantly more severe sarcoidosis than those with private insurance $(\mathrm{p}<0.0001)$, measured by FEV1 \% pred and FVC \% pred, although the number of involved organ systems was less strongly associated $(\mathrm{p}<0.01)$. Subjective measures of severity showed patients with no or other public insurance had more severe impairment $(\mathrm{p}<0.0001)$, as measured by dyspnoea, physical functioning, physical role limitations and general health.

Comorbidities and symptoms related to insurance status were allergies (more in the private/Medicare group), liver disease (more in the no or non-Medicare public insurance group), and smoking (more prevalent in the no or
non-Medicare public insurance group). Both heart rate and respiratory rate were higher in the no or non-Medicare public insurance group.

\section{Logistic regression analysis}

Logistic regression analysis was used to obtain final models with OR and 95\% confidence intervals (CI) for each of the eight significant severity outcomes tested (table 3 shows objective measures of severity and table 4 shows subjective measures). The Scadding score comparison was nonsignificant $(\mathrm{p}>0.05)$ for all predictors except $\geqslant 40$-yrs old $(\mathrm{OR}=1.45$, $\mathrm{p}=0.04)$ and female $(\mathrm{OR}=0.66, \mathrm{p}=0.03)$, and is, therefore, not included in tables 3 or 4 .

The following predictors are presented with their t-values; the OR and CI are available in tables 3 and 4. Blacks, compared with Whites, had more severe sarcoidosis based on objective disease measures (table 3 ). Blacks were more likely to have more organs involved $(\mathrm{p}<0.001)$, and a lower FVC \% pred $(\mathrm{p}<0.05)$. Cases having no or other public insurance were more likely to have low FVC \% pred $(\mathrm{p}<0.05)$, and those reporting trouble obtaining medicines were more likely to have more organs involved $(\mathrm{p}<0.01)$. Cases earning $<\mathrm{US}$ $\$ 20,000$ were more likely to have a low predicted FEV1\% pred $(\mathrm{p}<0.05)$.

Females had more severe disease based on the objective measure of low FVC $\%$ pred $(\mathrm{p}<0.01)$, (table 2$)$, and most subjective measures of disease (table 3 ). Females were more likely to report high levels of dyspnoea $(\mathrm{p}<0.05)$ and have poor physical functioning $(\mathrm{p}<0.001)$, physical role limitations $(\mathrm{p}<0.01)$, and poor general health $(\mathrm{p}<0.01)$. All subjective severity measures were worse for cases in the two lowest income categories. Those making $<$ US\$20,000 per year were more likely to have worse dyspnoea $(\mathrm{p}<0.001)$, poor physical functioning $(\mathrm{p}<0.001)$, physical role limitations $(\mathrm{p}<0.05)$, poor general health $(\mathrm{p}<0.01)$ and social functioning $(\mathrm{p}<0.001)$, compared with those making $\geqslant$ US $\$ 50,000$ annually. Cases with incomes between US\$20,000-50,000 were significantly more likely to have restricted social functioning.

Cases aged $\geqslant 40 \mathrm{yrs}$ had more severe disease by both objective (low FEV1 \% pred, FVC \% pred; both p $<0.001$ ) and subjective measures (dyspnoea, poor physical functioning, both at $\mathrm{p}<0.01)$, and physical role limitations $(\mathrm{p}<0.05)$.

The subjective measures of sarcoidosis severity, dyspnoea, poor physical functioning, and poor general health, were strongly associated with a patient's report that they had 
Table 3. - Logistic regression, odds ratio (OR) and 95\% confidence intervals $(\mathrm{Cl})$ for the effects of socioeconomic status and barriers to care on sarcoidosis severity at study entry by objective measures

\begin{tabular}{|c|c|c|c|c|c|c|c|}
\hline & \multicolumn{2}{|c|}{ More organs involved $^{\#}$} & \multicolumn{2}{|c|}{ Low FEV1 \% pred } & \multicolumn{3}{|c|}{ Low FVC $\%$ pred $^{+}$} \\
\hline & OR & CI & OR & CI & OR & & $\mathrm{CI}$ \\
\hline \multicolumn{8}{|l|}{ Demographical characteristics } \\
\hline \multicolumn{8}{|l|}{ Race } \\
\hline $\begin{array}{l}\text { Black } \\
\text { White }\end{array}$ & $1.78^{* * *}$ & $(1.31-2.41)$ & & NS & $1.48^{*}$ & & $(1.02-2.16)$ \\
\hline \multicolumn{8}{|l|}{ Sex } \\
\hline $\begin{array}{l}\text { Female } \\
\text { Male }\end{array}$ & & NS & & NS & $2.27 * *$ & & $(1.35-3.83)$ \\
\hline Age & & NS & $1.85^{* * *}$ & $(1.31-2.62)$ & $2.33 * * *$ & & $(1.61-3.30)$ \\
\hline $\begin{array}{l}\geqslant 40 \mathrm{yrs} \\
<40 \mathrm{yrs}\end{array}$ & & NS & & NS & & & \\
\hline \multicolumn{8}{|l|}{ Income } \\
\hline$<\mathrm{US} \$ 20,000$ & & & $1.6^{*}$ & $(1.06-2.42)$ & & NS & \\
\hline US $\$ 20,000-49,999$ & & & & NS & & NS & \\
\hline \multicolumn{8}{|l|}{ Barriers to care } \\
\hline \multicolumn{8}{|l|}{ Insurance status } \\
\hline $\begin{array}{l}\text { None or other/public } \\
\text { Private/Medicare }\end{array}$ & & NS & & NS & $1.71 *$ & & $(1.08-2.71)$ \\
\hline Trouble getting medications & $2.23^{* *}$ & $(1.27-3.92)$ & & NS & & NS & \\
\hline Missed $>1$ appointment & & NS & & NS & & NS & \\
\hline \multicolumn{8}{|l|}{ Comorbidities/symptoms } \\
\hline Self-reported general health & & NS & $1.27^{* *}$ & $(1.08-1.49)$ & $1.27 * *$ & & $(1.07-1.51)$ \\
\hline Allergies & & NS & & NS & $1.49^{*}$ & & $(1.04-2.13)$ \\
\hline High blood pressure & & NS & $0.65^{*}$ & $(0.45-0.95)$ & & NS & \\
\hline Liver disease & & NS & & NS & $0.37^{*}$ & & $(0.17-0.81)$ \\
\hline Ever smoking & & NS & $0.62 * *$ & $(0.45-0.86)$ & $0.68 *$ & & $(0.48-0.97)$ \\
\hline Height & & NS & $1.04 * * *$ & $(1.02-1.07)$ & $1.05^{* *}$ & & $(1.02-1.08)$ \\
\hline Respiratory rate & & NS & $1.06^{*}$ & $(1.01-1.11)$ & $1.07 * *$ & & \\
\hline
\end{tabular}

Race, sex and age were retained. For other predictors only those statistically significant $(\mathrm{p}<0.05)$ were retained. FEV1 \% pred: forced expiratory volume in one second per cent predicted; FVC $\%$ pred: forced vital capacity per cent predicted. NS: nonsignificant. ${ }^{\#}: n=696 ;{ }^{\uparrow}: n=672 ;{ }^{+}: n=673 .{ }^{*}$ : $\mathrm{p}<0.05 ; * *: \mathrm{p}<0.01 ; * * * \mathrm{p}<0.001$

difficulty obtaining medications $(\mathrm{p}<0.001)$. An association was also present for the number of organs involved $(\mathrm{p}<0.01)$. Insurance status was associated with a low FVC \% pred $(\mathrm{p}<0.05)$ and no subjective morbidity measures.

These associations with barriers to care and demographic characteristics remained despite the study groups attempts to adjust out the effects by including significant comorbidities and symptoms of the many that were included in the model (tables 2 and 3).

\section{Discussion}

Measures of income and other barriers to care are associated with sarcoidosis severity at initial presentation in descriptive analysis consistent with observations with severity and other diseases $[1,2]$. Low income and type of insurance were highly correlated with Black race, female sex, and barriers to care in descriptive analysis. Having low income and no or other public insurance may cumulatively discourage seeking medical care. Blacks are more likely to be unemployed or have low income jobs without insurance if employed [15]. ACCESS blacks were more likely to have family income of $<$ US\$20,000 (37 versus $9 \%$ of Whites) and to have other public insurance (16 as compared with $3 \%$ of Whites). Most other public insurance is Medicaid, health insurance for those impoverished, which pays providers less, restricts access to physicians, particularly specialists, by whom ACCESS cases were diagnosed [16]. The categorical nature of Medicaid eligibility is more problematic for young adult males, in contrast to females who may be eligible if pregnant or caring for children.
Even more restrictive than Medicaid is no insurance. Black males were those most likely to be uninsured (20 versus $8 \%$ for Black females and 3\% for all Whites). The relatively low number of Black males in the study (79 Black males versus 163 White males) may reflect these income and insurance barriers to care. When Black males and their families are comparably insured as in a health maintenance organisation, the rate of Black males with sarcoidosis is only slightly lower than that of Black females [17].

Barriers to care linked to healthcare costs may further delay recognition of asymptomatic or mild sarcoidosis. Low income ACCESS cases were less likely to have a regular physician when compared with higher income cases (73 versus $98 \%$ ). Other barriers to care i.e. delay in obtaining medicines, not seeing a physician when desired and reporting cost concerns about medical care, were also associated with sarcoidosis severity. For cases reporting delay in getting medicines and not calling a physician, cost was the most common reason given.

Physician visits require out-of-pocket expenses for related nonmedical expenses, such as transportation, babysitting, lost work income, as well as deductible and co-insurance expenditures. These costs discourage nonessential and routine care, which may account for lower rates of mild disease among those insured with low or intermediate income. However, once an individual presents to a physician, income and insurance do not delay sarcoidosis diagnosis, as shown in a substudy of the diagnostic pathway for ACCESS cases [18].

Logistical regression models support the relationship of sarcoidosis severity to SES and barriers to care. This 


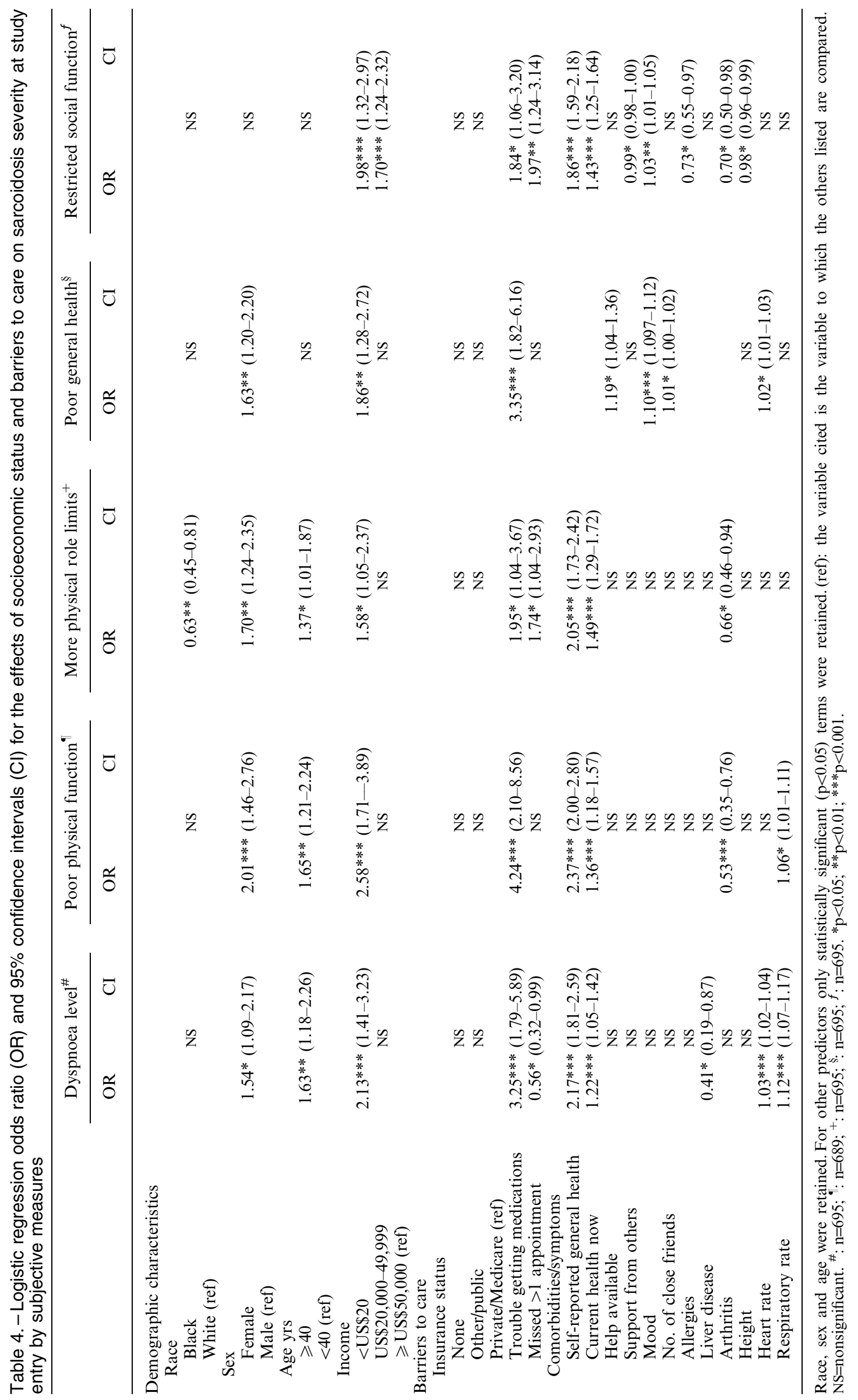


relationship is seen in both the models of objective and subjective measures of severity. Income is consistently associated with severity, even when analysed with insurance and comorbidities/other symptoms in the same model. Among other barriers to care, delay in obtaining medication is the most consistent predictor of disease severity. A multivariate regression of a case-control study of sarcoidosis also showed difficulty obtaining a prescription and not having a regular physician to be associated with cases [19].

Regarding demographic measures, cases aged $\geqslant 40 \mathrm{yrs}$ had more severe disease at presentation, by objective and subjective measures of diminished physical function and physical role limitations. Black race was associated with greater severity by objective, but not subjective, measures of disease at presentation, consistent with the possibility that Blacks are more likely to have financial barriers to care and delay seeking care. Black patients were less likely to have normal $\mathrm{FVC} \%$ pred at presentation, and Black males were less likely to present with normal FVC \% pred. The apparent severity of disease in Black males could be due to fewer Black males with asymptomatic and mild disease presenting early for diagnosis. ACCESS cases were significantly more likely to have private insurance and a regular physician than ACCESS telephone-area matched controls, suggesting people with better insurance and access to medical care are more likely diagnosed as cases.

By contrast to Black race, female sex was a predictor for all subjective, but no objective, measures. Perhaps, females experience sarcoidosis symptoms and limitations differently than males. Females in population surveys are more likely to report dyspnoea than males [20-21]. Females, compared with males, with minor respiratory infections report more shortness of breath [22]. In the National Health and Nutrition Examination Survey no. III (NHANES III), females had substantially lower FVC \% pred than males [23]. Others have reported using the SF-36 indices, that females with sarcoidosis were more likely than males to report poorer QoL [24]. Differences in interpretation of symptoms by sex may affect subjective perception of disease severity; females with sarcoidosis were more likely to be depressed [24]. Those depressed have a lowered threshold for discomfort, which may result in more negative responses to SF-36 questions on QoL [26-27]. Similarly lower income is a predictor of sarcoidosis severity at presentation for multiple measures of severity; low FEV1 \% pred, dyspnoea, and all the SF-36 QoL indices. National cross-sectional studies using diverse QoL measures indicate that lower income is associated with worse QoL scores [28-29]. When factors affecting QoL in low income populations are studied in a national study, the factors of employment status and activity limitations account for most of the variability in QoL. Other SES, demographic, and health insurance factors contribute little in additional explanation [29]. Dyspnoea and reduced pulmonary function due to sarcoidosis could result in activity limitation and contribute to the lower SF-36, physical function, and rate limit scores for those of lower income. Nevertheless, in the current study's analysis, lower income remains as a separate predictive factor for severity even when numerous other demographic, disease symptoms, and social factors are considered. However, QoL is an important aspect of care not fully recognised by physicians in providing sarcoidosis care. A recent study of ambulatory sarcoidosis patients argues that QoL provides important measures of patient experience with sarcoidosis not captured by physiological measures. They conclude that physicians' assessment of severity, which is primarily influenced by physiological measures, does not sufficiently acknowledge QoL aspects of sarcoidosis important to patients [30].

\section{Conclusions}

The current study's findings indicate that income, insurance, and cost barriers to care are significantly associated with sarcoidosis severity at presentation, even after adjusting for race, sex, age, and other comorbidities/symptoms. Cost barriers to care may cause some patients, particularly those with asymptomatic or early sarcoidosis, to delay presentation. Cost barriers reflect social policies restricting financial access to medical care and drugs. Although improved public education about sarcoidosis may increase awareness of sarcoidosis and its early symptoms, cost barriers will detrimentally affect decisions to seek care and comply with therapeutic recommendations. Identifying patients earlier would permit earlier therapeutic intervention (when appropriate) to permit symptomatic relief or effect disease course [3, $31,32]$. Reduced financial barriers to care are needed for earlier sarcoidosis detection and care.

Acknowledgements. Centres which were involed in ACCESS included: University of Cincinnati Medical Center, Cincinnati, OH; Mount Sinai Medical Center, New York, NY; Medical University of South Carolina, Charleston, SC; University of Pennsylvania and MCP-Hahnemann University Medical Centers, Philadelphia, PA; Georgetown University Medical Center, Washington, DC; University of Iowa College of Medicine, Iowa City, IA; Henry Ford Health System, Detroit, MI; Johns Hopkins University School of Medicine, Baltimore, MD; National Jewish Medical and Research Center, Denver, CO; Beth Israel Deaconess Medical Center, Boston, MA; and Clinical Trials and Surveys Corporation, Baltimore, MD, USA

\section{References}

1. Smedley BD, Stith AY, Nelson AR, eds. Committee on Understanding and Eliminating Racial and Ethnic Disparities in Health Care, Board on Health Sciences Policy. Unequal Treatment: Confronting Racial and Ethnic Disparities in Health Care, Washington, D.C., Institute of Medicine, 2002.

2. Auerbach JA, Krimgold BK, eds. Income, socioeconomic status, and health: Exploring the relationships. Washington, D.C., National Policy Association, 2001; 161p. (NPA Report, 299).

3. Statement on sarcoidosis. Joint Statement of the American Thoracic Society (ATS), the European Respiratory Society (ERS) and the World Association of Sarcoidosis and Other Granulomatous Disorders (WASOG) adopted by the ATS Board of Directors and by the ERS Executive Committee, February 1999. Am J Respir Crit Care Med 1999; 160: 736755.

4. Rabin DL, Richardson MS, Stein SR, Yeager H Jr. Sarcoidosis severity and socioeconomic status. Eur Respir $J$ 2001; 18: 499-506

5. Yeager H Jr, Rabin DL, Stein SR, et al. Pulmonary sarcoidosis: comparison of patients at a university and a municipal hospital. J Natl Med Assoc 1999; 91: 322-327.

6. Kajdasz DK, Judson MA, Mohr LC Jr, Lackland DT Geographic variation in sarcoidosis in South Carolina: its relation to socioeconomic status and health care indicators. Am J Epidemiol. 1999; 150: 271-278.

7. ACCESS Research Group. Design of a case control etiology study of sarcoidosis (ACCESS). J Clin Epidemiol 1999; 52: 1173-1186.

8. Judson MA, Baughman RP, Teirstein AS, Terrin ML, Yeager $\mathrm{H}$ Jr, ACCESS Research group. Defining organ 
involvement in sarcoidosis; The ACCESS proposed instrument. ACCESS Research Group. A Case-Control Etiologic Study of Sarcoidosis. Sarcoidosis Vasc Diffuse Lung Dis 1999; 16: 75-86.

9. Scadding JG. Prognosis of intrathoracic sarcoidosis in England: A review of 136 cases after five years observation. BMJ 1962; 2: 1165-1172.

10. Hankinson JL, Odencrantz JR, Fedan KB. Spirometric reference values from a sample of the general U.S. population. Am J Respir Crit Care Med 1999; 159: 179-87.

11. Watters LC, King TE, Schwarz MI, Waldron JA, Stanford RE, Cherniack RM. A clinical, radiographic, and physiologic scoring system for the longitudinal assessment of patients with idiopathic pulmonary fibrosis. Am Rev Respir Dis 1986; 133: 97-103.

12. Ware JE, Snow KK, Kosinski M, Gandek B. SF-36 Health Survey Manual and Interpretation Guide. Boston, MA, New England Medical Center; 1993.

13. Hosmer DW, Lemeshow S. Applied Logistic Regression. New York, USA, Wiley and Sons, 1989.

14. SAS Institute Inc., SAS/STAT Users Guide, Vol. 2, 4th Edn. Cary, NC: The SAS Institute; 1989. Watson, SD. Medicaid physician participation: patients, poverty, and physician selfinterest. Am J Law Med 1995; 21: 191-220.

15. US Bureau of the Census. Selected economic characteristics of persons and families, by sex and race: March, 1997. Available from: www.census.gov. Date last accessed: 11 November 2001.

16. Wayson SD. Medicaid physician participation: patients, poverty, and physician self-interest. Am J Law Med 1995; 21: 191-220.

17. Rybicki BA, Major MM, Popovich J Jr, Maliarik MJ, Iannuzzi MC. Racial differences in sarcoidosis incidence: a 5-year study in a health maintenance organization. Am $J$ Epidemiol 1997; 145: 234-241.

18. Judson MA, Thompson BW, Rabin DL, et al. The diagnostic pathway to sarcoidosis. Chest 2003; 123: 406-412.

19. Kajdasz DK, Lackland DT, Mohr LC, Judson MA. A current assessment of rurally linked exposures as potential risk factors for sarcoidosis. Ann Epidemiol 2001; 11: 111-117.

20. Viegi G, Paoletti P, Prediletto R, et al. Prevalence of respiratory symptoms in an unpolluted area of northern Italy. Eur Respir J 1988; 1: 311-318.

21. Gulsvik A. Prevalence and manifestations of obstructive lung disease in the city of Oslo. Scand J Respir Dis 1979; 60: 286-296.

22. Barsky AJ, Goodson JD, Lane RS, Cleary PD. The amplification of somatic symptoms. Psychosomatic Medicine 1988; 50: 510-519.

23. Harik-Khan RI, Fleg JL, Muller DC, Wise RA. The effect of anthropometric and socioeconomic factors on the racial difference in lung function. Am J Respir Crit Care Med 2001; 164: $1647-1654$.

24. De Vries J, Van Heck GL, Drent M. Gender differences in sarcoidosis: symptoms, quality of life, and medical consumption. Women Health 1999; 30: 99-114.

25. Chang B, Steimel J, Moller DR, et al. Depression in sarcoidosis. Am J Respir Crit Care Med 2001; 163: 329334.

26. Lautenbacher S, Spernal J, Schreiber W, Krieg JC. Relationship between clinical pain complaints and pain sensitivity in patients with depression and panic disorder. Psychosom Med 1999; 61: 822-827.

27. Dales RE, Spitzer WO, Schechter MT, Suissa S. The influence of psychological status on respiratory symptom reporting. Am Rev Respir Dis 1989; 139: 1459-1463.

28. Zahran HS, Moriarty DG, Zack MM, Kobau R. Public health and aging: health-related quality of life among lowincome persons aged 45-64 years: United States, 1995-2001. MMR weekly-DHHS, CDC. 52: 1120-1124.

29. Gold M, Franks P, Erickson P. Assessing the health of the nation: the predictive validity of a preference-based measure and self-rated health. Medical Care 1996; 32: 163-177.

30. Cox C, Donohue J, Brown C, Kataria Y, Judson M. Healthrelated quality of life of persons with sarcoidosis. Chest 2004; 125: 997-1004.

31. Gibson GJ, Prescott RJ, Muers MF, et al. British Thoracic Society sarcoidosis study: effects of long term corticosteroid treatment. Thorax 1996; 51: 238-247.

32. Pietinalho A, Tukiainen P, Haahtela T, Persson T, Selroos O. Early treatment of stage II sarcoidosis improves 5-year pulmonary function. Chest 2002; 121: 24-31. 